\title{
ANALISIS NILAI MORAL DALAM CERITA BERSAMBUNG "MBURU PUSAKA" KARYA AL ARIS PURNOMO
}

\author{
Herlina Setyowati, Eko Santosa \\ Universitas Muhammadiyah Purworejo \\ Pos-el: lina_poenya@ymail.com
}

\begin{abstract}
Abstrak
Karya sastra sebagai salah satu hasil kebudayaan manusia tentunya sangat menarik untuk dikaji kandungan pesan moralnya. Nilai-nilai pesan moral yang terdapat dalam cerita bersambung tersebut dapat dijadikan sebagai pedoman hidup dan dapat diterapkan dalam kehidupan seharihari. Dalam penelitian ini, cerita bersambung yang diteliti berjudul “Mburu Pusaka” karya Al Aris Purnomo yang dimuat di Majalah Jaya Baya. Cerita bersambung "Mburu Pusaka" ini dimuat bagian demi bagian dari episode 1 sampai 23, yaitu sejak edisi nomor 06 Bulan Oktober 2014 sampai dengan edisi nomor 27 Bulan Maret 2015. Tujuan penelitian ini ialah mendeskripsikan kandungan nilai moral di dalam cerita bersambung "Mburu Pusaka" karya Al Aris Purnomo. Teknik pengumpulan data yang digunakan adalah teknik pustaka dan teknik catat. Dalam teknik analisis data, peneliti menggunakan metode content analysis (analisis isi). Berdasarkan hasil penelitian, dapat diketahui bahwa cerbung "Mburu Pusaka" karya Al Aris Purnomo mengandung nilai moral baik meliputi sopan, ramah, percaya adanya Tuhan, menghormati perbedaan pendapat, peduli, rendah hati, akrab antara atasan dan bawahan, menghormati orang lain, mempunyai prinsip hidup, mengutamakan orang lain, bijaksana, jujur, dan cerdik; sedangkan nilai moral buruk meliputi mudah percaya pada orang lain, sakit hati pada orang lain, menukar barang milik orang lain, dan licik.
\end{abstract}

Kata kunci: nilai moral, cerita bersambung

\begin{abstract}
Literary work is one people cultures which is very interesting to be analyzed in terms of its moral values. Moral values found inside this serial story can become life guidance and it can be applied in daily life. In this research, the serial story which is going to be analysed entitles Mburu Pusaka (hunting for heritage) written by al Aris Purnomo contained in Jaya Baya magazine. This story is contained part by part from episode 1 until episode 23, since edition number 06 month of October 2014 until edition number 27 month of March 2015. The aim of this research is to describe the moral values found in serial story of Mburu Pusaka written by Al Aris Purnomo. Data collecting tecniques used are literary and documentary note-taking analysis. Data analysis technique used is content analysis method. Based on reserach result, it is found out that the Mburu Pusaka story contains good moral values such as polite, friendly, respecting different opinions, care, humble, being chummy between boss and staff, respecting others, accentuating others, wise, honest, and smart while bad moral values such as easily believing in others, resentful to othres, exchange other's goods, and sly.
\end{abstract}

Key words: moral values, serial story

\section{PENDAHULUAN}

Karya sastra sebagai salah satu hasil kebudayaan manusia tentunya sangat menarik untuk dikaji dan dibicarakan. Pengkajian dan pembicaraan itu dapat dilakukan dari sudut nilainya, seperti nilai seni, nilai ajaran hidup, maupun nilai-nilai yang lain. Nilai seni berkaitan dengan keindahan (estetis), sedangkan 
nilai ajaran hidup berhubungan dengan amanat atau pesan yang disampaikan pengarang kepada pembaca. Perumusan dari semua itu dapat tersurat maupun tersirat. Dengan demikian, sesuai dengan pernyataan Horace dulce et utile atau sweet and useful, yakni menyenangkan dan berguna (Wellek \& Warren, 1995: 25). Menyenangkan dan berguna dalam hal ini berhubungan dengan bahasa dan isi atau kandungan makna dan nilai-nilai yang terdapat di dalamnya, baik makna tersurat maupun makna tersirat.

Karya sastra Jawa banyak ragamnya, antara lain cerkak (cerita cekak), cerbung (cerita sambung), novel, geguritan. Dalam hal ini, peneliti mengkaji salah satu karya sastra yang sudah sangat dikenal oleh masyarakat luas yaitu cerbung (cerita sambung). Cerbung yang dalam bahasa Indonesia dikenal dengan "cerita bersambung" merupakan karya sastra yang sudah diketahui banyak orang. Cerbung yang diteliti berjudul "Mburu Pusaka" karya Al Aris Purnomo yang dimuat di Majalah Jaya Baya. Cerbung "Mburu Pusaka" ini dimuat bagian demi bagian dari episode 1 sampai 23, sejak edisi nomor 06 Bulan Oktober 2014 sampai dengan edisi nomor 27 Bulan Maret 2015.

Cerita yang ditulis oleh pengarang memuat suatu nilai moral. Nilai moral yang terkandung dalam cerbung mengandung pesan atau amanat, baik yang tersurat maupun tersirat. Nilai moral yang terdapat dalam cerbung tersebut juga dapat dijadikan sebagai pedoman hidup yang diterapkan dalam kehidupan sehari-hari. Dalam cerbung ini, nilai moral yang terkandung lebih banyak yang bersifat tersurat sehingga pembaca harus lebih memahami agar dapat mengerti pesan apa yang ingin disampaikan oleh pengarang. Tujuan penelitian ini ialah mendeskripsikan nilai moral baik dan nilai moral buruk yang terkandung dalam Cerbung "Mburu Pusaka" karya Al Aris Purnomo. Adapun manfaat penelitian ini secara praktis ialah dapat dijadikan sebagai pedoman dalam ber- sikap dan bertingkah laku dalam kehidupan sehari-hari.

\section{TEORI DAN METODE}

Wellek \& Warren (1995: 12) mengemukakan definisi sastra meliputi: (1) sastra ialah segala sesuatu yang tertulis atau tercetak; (2) sastra ialah segala buku yang dianggap menonjol karena bentuk dan ekspresi sastranya; (3) sastra diterapkan pada seni sastra, yaitu dipandang sebagai karya imaginatif. Sudjiman (1986: 68) juga mengemukakan bahwa sastra adalah karya lisan atau tertulis yang memiliki berbagai ciri keunggulan seperti keorisinalan, keartistikan, serta keindahan dalam isi dan ungkapannya. Selanjutnya, Atar Semi (dalam Endraswara, 2008: 38) mengemukakan ada tiga tugas dan fungsi sastra, yakni sebagai berikut. Pertama, sebagai alat penting pemikir-pemikir untuk menggerakkan pembaca kepada kenyataan dan menolongnya mengambil suatu keputusan bila mendapat masalah. Pengarang bertugas mengikuti dan memikirkan tentang budaya dan nilai-nilai bangsanya pada masa hidup untuk kemudian dicurahkan ke dalam karya sastra yang baik. Salah satu ukuran sastra yang baik ialah sastra yang dapat menggambarkan kebudayaan masyarakat pemiliknya pada zamannya. Kedua, berfungsi sebagai alat untuk meneruskan tradisi suatu bangsa, baik kepada masyarakat sezaman maupun generasi mendatang. Dengan kata lain alat penerus tradisi dari generasi ke generasi berikutnya. Ketiga, menjadikan sastra sebagai tempat pemberian perhatian, pemertahanan, dan penyebarluasan nilai kemanusiaan secara wajar, terutama di tengah-tengah kehidupan modern yang ditandai dengan majunya sains dan pesatnya teknologi.

Menurut Muchson (2012: 2), moral adalah ajaran tentang laku hidup yang baik berdasarkan pandangan hidup atau agama tertentu. Moral yang berasal dari kata "mores", artinya mengungkapkan dapat atau tidaknya suatu perbuatan atau tindakan yang diterima oleh 
sesama manusia dalam hidup kemasyarakatan (Darmadi, 2009: 53). Dalam kenyataannya, pandangan baik buruknya tingkah laku tidaklah sama pemikiran satu dengan yang lain. Pengertian moral secara umum mengacu pada ajaran tentang baik buruk yang diterima umum mengenai perbuatan, sikap, kewajiban akhlak, budi pekerti, dan susila (KBBI, 2008: 1041).

Moralitas adalah kesesuaian sikap dengan norma atau hukum batiniah (Muchson, 2012: 6). Dalam hal ini, seseorang yang mematuhi hukum lahiriah dipandang bukan karena takut pada sanksi, tetapi sebagai kesadaran sendiri karena mengandung nilai kebaikan. Perkembangan moral manusia ditentukan oleh kemampuan seseorang dalam merespon lingkungan yang mereka lakoni sehingga akan terbentuk kembali pengetahuan yang baru menyangkut moral dan kematangan (Darmadi, 2009: 124). Melihat kenyataan tersebut, fungsi moral dalam suatu masyarakat memegang peranan yang sangat penting dalam mewujudkan proses budi pekerti yang mengarahkan pada kemampuan berfikir rasional, berani mengambil keputusan, dan bertanggung jawab atas perilakunya berdasarkan hak dan kewajiban. Gazalba dalam Lubis (2008: 11) mendefinisikan moral sebagai ajaran-ajaran, patokanpatokan, kumpulan peraturan, dan ketepatan lisan atau tulisan tentang bagaimana manusia harus hidup dan bertindak agar menjadi manusia yang baik.

Berdasarkan pengertian moral yang telah dikemukakan di atas, dapat disimpulkan bahwa moral merupakan segala sesuatu yang berkaitan dengan ajaran atau patokan baik dan buruk mengenai perbuatan, sikap, dan budi pekerti seseorang. Dengan itu dapat terbentuk pribadipribadi yang memiliki sikap positif dan kesadaran moral yang dapat membedakan baik dan buruk, hal yang boleh dan tidak boleh dilakukan, serta dapat berfikir secara rasional. Setiap individu dalam bersikap, bertingkah laku, dan bergaul haruslah memperhatikan norma- norma atau aturan yang berlaku dalam masyarakat.

Pengertian moral dalam karya sastra itu sendiri tidak berbeda dengan moral secara umum, yaitu yang berhubungan dengan sifatsifat luhur kemanusiaan (baik dan buruk) serta penerapan moral dalam bersikap dan bertingkah laku. Moral dalam karya sastra biasanya dimaksudkan sebagai petunjuk dan pedoman yang bersifat praktis untuk pembaca dalam kehidupan sehari-hari. Moral dalam cerita menurut Kenny dalam Nurgiyantoro (2012: 321) biasanya dimaksudkan sebagai suatu saran yang berhubungan dengan ajaran moral tertentu yang bersifat praktis yang dapat diambil atau ditafsirkan lewat cerita sehingga pembaca dapat mengambil hikmah dari pesan-pesan moral yang disampaikan. Menurut Nurgiyantoro (2012: 323-324), jenis ajaran moral dalam karya sastra dibagi menjadi: 1) persoalan hubungan manusia dengan diri sendiri; 2) hubungan manusia dengan manusia lain dalam lingkup sosial; 3) hubungan manusia dengan lingkungan alam; dan 4) hubungan manusia dengan Tuhannya.

Persoalan hidup manusia dengan dirinya sendiri dapat bermacam-macam jenis dan tingkat intensitasnya. Tentu saja tidak lepas kaitannya dengan persoalan hubungan manusia dengan diri sendiri dan dengan Tuhan seperti eksistensi diri, harga diri, rasa percaya diri, takut, rindu, dendam, kesepian, keterombangambingan antara beberapa pilihan, dan lainlain yang lebih bersifat melibat ke dalam diri dan kewajiban seseorang individu (Nurgiyantoro, 2012: 324). Masalah-masalah yang hubungannya dengan sesama manusia itu antara lain dapat berwujud persahabatan yang kokoh ataupun rapuh, kesetiaan, penghianatan, kekeluargaan: hubungan suami istri, orang tua kepada anak, cinta kasih terhadap suami atau istri, anak terhadap orang tua, sesama maupun tanah air, hubungan buruh kepada majikan, hubungan atasan dengan bawahan dan lain- 
lain yang melibatkan interaksi antarmanusia (Nurgiyantoro, 2012: 325).

Untuk menemukan moral yang terdapat dalam karya sastra tidaklah mudah karena untuk memahaminya harus diperlukan adanya analisis terhadap karya sastra. Dengan analisis dapat ditemukan nilai-nilai yang terdapat pada sebuah karya sastra sehingga nilai-nilai moral yang terdapat dalam karya sastra serta pesan moral yang disampaikan dapat membawa dampak dan perubahan yang baik kepada pembaca.

Sumber data dalam penelitian ini adalah Cerita Bersambung "Mburu Pusaka" karya Al Aris Purnomo yang dimuat dalam Majalah Jaya Baya edisi nomor 06 Bulan Oktober 2014 sampai dengan edisi nomor 27 Bulan Maret 2015. Sementara itu, data dalam penelitian ini adalah kutipan kalimat yang terdapat dalam Cerita Bersambung "Mburu Pusaka" karya Al Aris Purnomo yang mengandung nilai moral. Adapun teknik pengumpulan data yang digunakan untuk mengetahui Cerita Bersambung "Mburu Pusaka" karya Al Aris Purnomo adalah menggunakan teknik pustaka dan teknik catat. Teknik pustaka adalah suatu teknik yang menggunakan sumber-sumber tertulis untuk memperoleh data (Subroto, 1992: 42). Sumber-sumber tertulis dapat berwujud karya sastra, buku bacaan umum, dan karya ilmiah. Sumber tertulis dalam penelitian ini ialah Cerita Bersambung "Mburu Pusaka" karya Al Aris Purnomo. Selanjutnya, teknik pengumpulan data menggunakan teknik catat. Teknik catat merupakan salah satu jenis teknik lanjutan. Teknik catat yaitu pencatatan pada kartu data yang dilanjutkan dengan klasifikasi (Sudaryanto, 1988: 4). Kutipan kata atau kalimat yang mengandung nilai moral baik dan nilai moral buruk yang terdapat dalam Cerita Bersambung "Mburu Pusaka" karya Al Aris Purnomo dicatat dan diklasifikasikan dalam kartu data.

\section{HASIL DAN PEMBAHASAN}

Dalam Cerita Bersambung "Mburu Pusaka" karya Al Aris Purnomo ini banyak kandungan nilai moralnya yang dapat dimanfaatkan dalam hidup bermasyarakat. Perbuatan dan sikap tokoh yang tergambar di dalam cerita bersambung ini dapat dijadikan cerminan nilai moral yang dianut oleh masyarakat Jawa pada umumnya karena keseluruhan latar di dalam cerita bersambung ini berada di Jawa Tengah. Berikut ini disajikan pembahasan terhadap nilai moral Cerita Bersambung "Mburu Pusaka" karya Al Aris Purnomo.

\section{Moral Baik}

\section{Sopan}

Sopan artinya hormat dan takzim, tertib menurut adat yang baik; beradab (tingkah laku, tutur kata, pakaian dan sebagainya.); tahu adat, baik budi bahasanya, baik kelakuannya (tidak lacur, tidak cabul) (KBBI, 2008: 1493). Perilaku sopan ditunjukkan oleh sikap Nurcahya yang akan memasuki pintu gerbang berwujud gapura sebuah rumah dengan mengucapkan salam pada penghuni rumah. Berikut ini kutipan yang menunjukkan sikap sopan.

"Kula nuwun," wong kang mau ngunekake klinthingan uluk salam.

(episode 1: 1)

\section{Terjemahan:}

"Permisi,' orang yang membunyikan lonceng itu mengucapkan salam.' (episode 1: 1)

Kutipan di atas menggambarkan sikap sopan Nurcahya yang akan memasuki gapura sebuah rumah dengan mengucapkan "kula nuwun" pada penghuni rumah. Rumah tersebut terkenal dengan sebutan "Griya Wening". Kebetulan ada Karmidi yang sedang menyapu halaman rumah. Karmidi adalah seorang penjaga rumah Griya Wening tersebut yang bertugas membersihkan rumah. Ucapan "kula nuwun" dari Nurcahya tersebut ditujukan 
pada Karmidi yang menuju ke arahnya. Karmidi kemudian menanyakan keperluan orang yang ada di depan gapura itu. Di dalam kebudayaan masyarakat Jawa, ucapan "kula nuwun" memberikan makna permohonan izin. Sikap ini menunjukkan tingkat kesopanan yang tinggi karena sebelum seseorang diizinkan untuk memasuki rumah, orang tersebut harus meminta izin terlebih dahulu kepada penghuni rumah.

\section{Ramah}

Ramah artinya baik hati dan menarik budi bahasanya; manis tutur kata dan sikapnya (terhadap semua orang); suka bergaul, dan menyenangkan dalam pergaulan (KBBI, 2008: 1254). Sikap ramah ditunjukkan dengan tutur kata yang manis dan pergaulan yang akrab. Orang yang ramah biasanya banyak bicara pada orang lain. Sikap ramah ini ditunjukkan oleh tokoh Karmidi saat Gunar Sudigdo berpamitan. Berikut ini kutipannya.

"Menapa lajeng kondur kemawon? Boten ngenggar-enggar penggalih ing Wadhuk Gajah Mungkur rumiyin?"pitakone Karmidi. (episode 2: 1)

\section{Terjemahan:}

"Apa langsung ingin pulang? Tidak berwisata dulu di waduk Gajah Mungkur?' tanya Karmidi.' (episode 2: 1)

Kutipan di atas menggambarkan sikap ramah Karmidi kepada Gunar Sudigdo. Karmidi adalah penjaga Rumah Griya Wening. Walaupun begitu, dia selalu terlihat ramah pada tamu yang datang di Rumah Griya Wening. Saat itu Gunar Sudigdo akan meninggalkan Rumah Griya Wening. Spontan Karmidi bertanya pada tamunya apakah akan langsung pulang. Karmidi juga menyarankan tamunya untuk melepas penat dengan berwisata di Waduk Gajah Mungkur.

Sikap ramah juga ditunjukkan oleh Gunar Sudigdo. Walaupun Gunar Sudigdo adalah orang kaya dan seorang pemimpin perusaha- an, dia tidak segan menjawab pertanyaan Karmidi, seorang penjaga rumah. Berikut kutipannya.

"Sanes wekdal kemawon," wangsulane Gunar Sudigdo grapyak, ora nuduhke yen dheweke kuwi wong mbrewu sing padatan angkuh sikepe. (episode 2: 1)

\section{Terjemahan:}

'Lain waktu saja,' jawab Gunar Sudigdo ramah, tidak menunjukkan sebagai orang kaya yang biasanya angkuh.' (episode 2: 1)

Kutipan di atas menggambarkan sikap ramah Gunar Sudigdo yang sudi menjawab pertanyaan Karmidi. Status sosial tidak menjadi halangan seseorang untuk berbuat ramah. Gunar Sudigdo adalah orang yang berstatus sosial tinggi, sedangkan Karmidi adalah orang yang berstatus sosial rendah. Sikap ramah seperti ini perlu ditiru karena membina hubungan baik dalam pergaulan di masyarakat akan membentuk suasana kehidupan masyarakat yang damai dan tentram.

Selain sikap Karmidi dan Gunar Sudigdo, sikap Nurcahya berikut ini juga menunjukkan sikap ramah. Berikut kutipannya.

"Kula nggih nyuwun pamit, Pak Karmidi. Mbenjing kepanggih malih," Nurcahya pamitan kanthi semanak. (episode 2: 1)

\section{Terjemahan:}

"Saya juga ingin berpamitan, Pak Karmidi. Besok berjumpa lagi.' Nurcahya berpamitan dengan akrab.' (episode 2: 1)

Kutipan di atas menggambarkan sikap ramah Nurcahya kepada Karmidi. Status sosial antara Nurcahya dan Karmidi sama, yakni sama-sama bekerja untuk orang lain. Nurcahya bekerja sebagai sopir pribadi Gunar Sudigdo, sedangkan Karmidi bekerja sebagai penjaga Rumah Griya Wening milik Dirga Swandaru. Meskipun demikian, Karmidi lebih tua dibandingkan Nurcahya. Oleh karena itu, dengan sopan dan ramah Nurcahya berpamitan kepada Karmidi. Sikap yang demikian harus terus 
dipelihara agar ketentraman hidup di masyarakat tetap terjaga.

\section{Percaya Adanya Tuhan}

Percaya artinya 1) mengakui atau yakin bahwa sesuatu memang benar atau nyata; 2) menganggap atau yakin bahwa sesuatu itu benar-benar ada; 3) menganggap atau yakin bahwa seseorang itu jujur (tidak jahat dan sebagainya); 4) yakin benar atau memastikan akan kemampuan atau seseorang atau sesuatu (bahwa akan dapat memenuhi harapannya dan sebagainya) (KBBI, 2008: 1158). Percaya adanya Tuhan ialah mengakui dan meyakini bahwa Tuhan benar-benar ada. Sikap percaya adanya Tuhan ditunjukkan oleh Gunar Sudigdo yang berkata pada Nurcahya bahwa dia benar-benar percaya Tuhan dan kekuasaannya itu ada. Berikut ini kutipannya.

\section{"Takkandhani ya, Nur. Aku banget per- caya marang anane Gusti lan uga pa- nguwasane. Aku uga duwe kapitayan, kalamun panguwasane Gusti kuwi kanthi lantaran, salah sijine liwat pusaka-pusaka, mula aku seneng ngramput pusaka-pusaka kuwi mau. Saliyane kuwi, aku duwe sedya kanggo nglestarekake tilarane para nimpuna duking nguni, kang wujud asil karya mi- runggan kalebu pusaka-pusaka kuwi." (episode 2: 2)}

\section{Terjemahan:}

"Aku beri tahu ya, Nur. Aku sangat percaya kepada adanya Tuhan dan kekuasaannya. Aku juga mempunyai kepercayaan bahwa kekuasaan Tuhan itu melalui perantara, salah satunya melalui pusaka-pusaka, oleh karenanya aku senang merawat pusaka-pusaka itu. Selain itu, aku mempunyai keinginan untuk melestarikan peninggalan para cerdik pandai zaman dahulu, yang berwujud hasil karya khusus, termasuk pusaka-pusaka itu." (episode 2: 2)

Kutipan di atas menggambarkan sikap Gunar Sudigdo yang sangat percaya adanya Tuhan, yang ditunjukkan dengan pernyataan
"Aku banget percaya marang anane Gusti lan uga panguwasane". Gunar Sudigdo percaya bahwa Tuhan ada melalui kekuasannya, salah satunya melalui pusaka peninggalan nenek moyang. Oleh karena itu, Gunar Sudigdo senang merawat pusaka. Selain itu, dia juga ingin melestarikan peninggalan nenek moyang yang berwujud pusaka itu. Dari pernyataan Gunar Sudigdo tersebut, jelas bahwa dia menyukai pusaka karena ingin melestarikan hasil kebudayaan nenek moyang. Apabila pusaka yang ia miliki mempunyai kekuatan, Gunar Sudigdo percaya bahwa kekuatan itu berasal dari Tuhan, bukan dari yang lain.

Pernyataan Gunar Sudigdo yang percaya terhadap Tuhan dan kekuasaannya juga muncul pada kutipan berikut ini.

\section{"Aku percaya yen wujud panguwasane Gusti kuwi maneka warna. Salah sijine yakuwi... lumantar anane pusaka-pusaka kang duwe daya linuwih kuwi mau." (episode 13: 2)}

\section{Terjemahan:}

"Aku percaya bahwa wujud kekuasaan Tuhan itu beraneka rupa. Salah satunya yaitu melalui pusaka-pusaka yang mempunyai kekuatan lebih itu." (episode 13: 2)

Kutipan di atas menggambarkan sikap Gunar Sudigdo yang sangat percaya bahwa kekuatan yang ada di dalam pusaka yang ia simpan berasal dari Tuhan. Sikap Gunar Sudigdo seperti yang sudah ditunjukkan dalam kutipan-kutipan di atas harus dicontoh. Sebagai insan yang beriman, seseorang harus percaya bahwa segala kekuatan yang tersimpan dalam sebuah benda itu berasal dari Tuhan semata. Kecintaan kita terhadap hasil budaya bangsa perlu dipupuk sebagai bentuk penghargaan kita kepada nenek moyang yang telah menghasilkan sebuah kebudayaan, salah satunya yakni pusaka keris. 


\section{Menghormati Perbedaan Pendapat}

Hormat artinya 1) menghargai (takzim, khidmat); 2) perbuatan yang menandakan rasa khidmat atau takzim (seperti menyembah, menunduk); 3) menaruh (memberi) penghargaan; 4) takzim; sopan (KBBI, 2008: 556). Menghormati artinya 1) menaruh hormat kepada; hormat (takzim, sopan) kepada; 2) menghargai; menjunjung tinggi; 3) mengakui dan menaati (tentang aturan, perjanjian) (KBBI, 2008: 556). Menghormati perbedaan pendapat artinya menghargai pendapat orang lain yang berbeda. Dalam melakukan musyawarah atau berdiskusi tentang suatu hal, kadang muncul perbedaan pendapat. Perbedaan pendapat itu muncul karena sudut pandang yang dipakai oleh orang yang satu dengan orang yang lain berbeda. Meskipun begitu, seseorang harus menghormati perbedaan pendapat itu. Berikut ini kutipan tentang perbedaan pendapat yang terjadi antara Gunar Sudigdo dengan Nurcahya.

"Miturut kowe, Bapa Dirga Swandaru kae bisa dipercaya?"

"Wah, kula dereng njlumati bab punika. Ning ing batos kula kraos rangu-rangu. Pangapunten bab menapa ingkang ndadosaken kula rangu-rangu."

"Yen aku percaya kok, Nur. Yen krungu tembunge nalika bab ragad dirembug yen wis kasil, kuwi nuduhake yen dheweke pancen tenanan anggone bakal ngupadi pasangane Kyai Branti iki, katone bab ragad kuwi bab sing nomer keri dhewe."

"Mugi-mugi mekaten."

"Nanging yen kowe rangu-rangu, kuwi ya malah meneri, ateges kowe bisa menehi panemu marang aku ngenani bab-bab sing miturut kowe nyleneh lan nyalawadi..." (episode 2: 2)

\section{Terjemahan:}

"Menurutmu, Bapak Dirga Swandaru itu bisa dipercaya?'

"Wah, saya belum memikirkan hal itu. Tetapi dalam batin saya merasa ragu. Saya tidak tahu hal apa yang membuat saya ragu-ragu."
"Kalau aku percaya, Nur. Apabila mendengar perkataannya saat membahas biaya bila sudah berhasil, itu menunjukkan dia betul-betul akan mencari pasangan Kyai Branti, sepertinya masalah biaya menjadi nomor terakhir."

"Semoga saja begitu."

"Tetapi, bila kamu ragu-ragu, itu malah lebih baik, artinya kamu bisa memberikan pendapatmu mengenai hal-hal yang menurutmu aneh dan mencurigakan." (episode 2: 2)

Kutipan di atas merupakan dialog antara Gunar Sudigdo dengan Nurcahya. Gunar Sudigdo menanyakan kepada Nurcahya mengenai pendapatnya terhadap sosok Dirga Swandaru. Nurcahya menyatakan bahwa dia masih merasa ragu dengan sosok Dirga Swandaru itu. Akan tetapi, Nurcahya tidak mengerti keraguan mengenai hal apa. Sebaliknya, Gunar Sudigdo sangat mempercayai Dirga Swandaru. Apalagi saat Gunar Sudigdo menanyakan biaya pada Dirga Swandaru. Dirga Swandaru menjawab bahwa masalah biaya menjadi nomor terakhir. Hal itu memperkuat keyakinan Gunar Sudigdo terhadap Dirga Swandaru bahwa dia tidak memikirkan materi. Namun, perbedaan pendapat antara Gunar Sudigdo dan Nurcahya itu tidak membuat hubungan keduanya menjadi renggang. Gunar Sudigdo berpikir bahwa sikap ragu-ragu Nurcahya terhadap Dirga Swandaru itu lebih baik, karena Nurcahya dapat memberikan pendapatnya pada Gunar Sudigdo bila menemukan keanehan, seperti yang ditunjukkan pada pernyataan "Nanging yen kowe rangu-rangu, kuwi ya malah meneri, ateges kowe bisa menehi panemu marang aku ngenani bab-bab sing miturut kowe nyleneh lan nyalawadi...".

Dari uraian di atas jelas bahwa Gunar Sudigdo tidak memaksakan pendapatnya kepada Nurcahyo. Gunar Sudigdo sangat menghormati perbedaan pendapat itu. Apalagi dia mengganggap bahwa pendapat Nurcahya yang bertentangan dengannya itu lebih baik sehingga saat terjadi sesuatu yang aneh dan 
mencurigakan akan dapat teratasi dengan cepat. Sikap yang demikian perlu ditiru karena dalam menilai sesuatu sudut pandang antara orang yang satu dengan yang lain kadang berbeda, sehingga muncul perbedaan pendapat. Perbedaan pendapat ini bisa menguntungkan karena kedua orang yang berbeda pendapat itu bisa saling mengingatkan.

\section{Peduli}

Peduli artinya mengindahkan; memperhatikan; menghiraukan (KBBI, 2008: 1138). Sikap peduli ini ditunjukkan oleh Gunar Sudigdo yang melihat seseorang terjatuh dari kendaraan dan meminta sopirnya untuk menghentikan laju kendaraan yang ditumpanginya. Berikut ini kutipannya.

"Mandheg sik, Nur! Delengen sing tiba kuwi mau. Katone tiba merga kaget weruh awake dhewe bakal menggok ngulon," tembunge Gunar Sudigdo. (episode 3: 1)

\section{Terjemahan:}

"Berhenti, Nur! Lihat yang jatuh itu. Sepertinya terjatuh karena kaget melihat kita akan berbelok ke barat,' kata Gunar Sudigdo.' (episode 3: 1)

Kutipan di atas merupakan gambaran kepedulian Gunar Sudigdo saat melihat seseorang terjatuh dari kendaraannya. Gunar Sudigdo meminta sopirnya untuk menghentikan laju kendaraan kemudian melihat kondisi korban. Dia merasa bahwa korban terjatuh karena kaget melihat kendaraan yang ditumpanginya tiba-tiba berbelok ke arah barat.

Selain Gunar Sudigdo, Nurcahya juga menunjukkan kepeduliannya terhadap korban. Berikut kutipannya.

"Sampeyan boten napa-napa?" takone Nurcahya marang wong sing mau numpaki pit montor sing isih nganggo helm brukut. (episode 3: 1)

Terjemahan:

'Anda tidak apa-apa?' tanya Nurcahya kepada orang yang tadi menaiki sepeda motor dan masih mengenakan helm.' (episode 3: 1)

Kutipan di atas merupakan gambaran kepedulian Nurcahya kepada korban yang terjatuh dari motor. Nurcahya menanyakan keadaan si korban. Kepedulian seperti ini masih bisa kita jumpai di Indonesia. Apabila ada seseorang yang terjatuh dari kendaraan, orang lain yang melihat akan mendekati dan memastikan kondisinya. Sikap peduli ini harus terus dipupuk supaya kehidupan di tengah masyarakat kita sikap tolong-menolong dan rasa peduli terhadap sesama terus berjalan. Selain kutipan di atas, kutipan di bawah ini juga menunjukkan kepedulian Nurcahya kepada orang lain.

"Kula mawon sing nimba, Pak." (episode 6: 2)

\section{Terjemahan:}

'Saya saja yang menimba (mengambil air dari sumur), Pak' (episode 6: 2)

Kutipan di atas menggambarkan kepedulian Nurcahya pada Gunar Sudigdo. Saat itu Gunar Sudigdo berusaha untuk mengambil air dari sumur. Melihat hal itu, Nurcahya menawarkan diri untuk membantu. Namun, tawaran bantuan itu ditolak dengan halus oleh Gunar Sudigdo. Sebagai anak buah, tentu saja Nurcahya ingin membantu atasannya. Kepedulian semacam ini perlu dipelihara agar sikap tolong-menolong di tengah masyarakat dapat dijaga.

\section{Rendah Hati}

Rendah hati yakni hal (sifat) rendah hati (KBBI, 2008: 1291). Sifat rendah hati misalnya tidak sombong; tidak angkuh. Sifat rendah hati ini ditunjukkan oleh tokoh Nurcahya yang meminta maaf kepada seorang gadis yang terjatuh dari motornya yang disebabkan oleh ketidakhati-hatian Nurcahya. Berikut ini kutipannya. 
"Nyuwun pangapunten yen Njenengan dhawah," Nurcahya ngejak salaman. (episode 3: 1)

\section{Terjemahan:}

"Mohon maaf bila Anda terjatuh,' Nurcahya mengajak berjabat tangan.'

(episode 3: 1)

Kutipan di atas menggambarkan sifat rendah hati Nurcahya yang mau mengakui kesalahannya. Sebenarnya Nurcahya sendiri tidak tahu apa yang menyebabkan gadis itu terjatuh, tetapi Nurcahya merasa perlu meminta maaf.

Di bawah ini juga digambarkan sifat rendah hati Nurcahya saat dipuji oleh Dyah Pramesthi.

\begin{abstract}
"Ah... ya ora hebat. Kebeneran wae wongwong mau padha nyepelekake, mula banjur kelangan kapercayan dhiri...." (episode 12: 1)
\end{abstract}

\section{Terjemahan:}

"Ah... ya tidak hebat. Kebetulan saja orang itu menyepelekan, lantas kehilangan kepercayaan diri."

Kutipan di atas menggambarkan sifat Nurcahya yang tetap merendah saat dipuji oleh Dyah Pramesthi. Pujian itu tidak membuatnya sombong. Nurcahya tetap merendah meskipun dia telah berhasil mengusir para penjahat yang akan menculik Dyah Pramesthi. Nurcahya berdalih bahwa keberhasilannya itu karena para penjahat itu menyepelekannya sehingga kehilangan kepercayaan diri.

Sifat rendah hati juga ditunjukkan oleh gadis yang bernama Tyas Widuri. Gadis ini terjatuh dari motor karena kaget saat tahu ada mobil yang tiba-tiba berbelok. Dia merasa bahwa yang membuatnya jatuh bukan kesalahan mobil itu, tetapi kesalahannya sendiri yang mengendarai motor sambil melamun. Berikut ini kutipannya.
"Boten. Njenengan boten lepat. Kula sing lepat, wong radi ngalamun," wanita kuwi nampani salamane Nurcahya. (episode 3: 1)

\section{Terjemahan:}

"Tidak. Anda tidak bersalah. Saya yang salah, sedang melamun.' wanita itu menerima tangan Nurcahya.' (episode 3: 1)

Kutipan di atas menggambarkan Tyas Widuri yang mengakui bahwa dirinya yang bersalah, bukan orang lain. Sifat seperti ini jarang sekali ditemui di tengah masyarakat. Umumnya, saat seseorang tertimpa kemalangan, orang tersebut akan menyalahkan orang lain atas kemalangan itu. Namun tidak untuk Tyas Widuri. Dia mengakui keasalahannya sendiri. Oleh karena itu, saat Gunar Sudigdo menyatakan bersedia memberi ganti rugi, Tyas Widuri menolaknya. Dia tetap bersikukuh bahwa kecelakaan itu terjadi karena dirinya sendiri. Sikap seperti ini perlu dipelihara agar terjadi keharmonisan di tengah masyarakat.

\section{Akrab antara Atasan dan Bawahan}

Akrab artinya dekat dengan erat (tentang persahabatan); intim (KKBI, 2008: 28). Keakraban artinya hal (keadaan) akrab. Keakraban yang sering dilihat di tengah masyarakat biasanya keakraban antara anggota keluarga dan keakraban dengan seorang sahabat. Keakraban antara seorang pimpinan (atasan) dan anak buah (bawahan) jarang sekali terjadi. Akan tetapi, di dalam Cerita Bersambung "Mburu Pusaka" karya Al Aris Purnomo ini keakraban antara atasan dan bawahan diceritakan dengan baik. Wujud keakrabannya dapat dilihat dalam kutipan berikut ini.

"Wong loro sing siji sopir sing siji bos kuwi padha ngguyu bebarengan, katon akrab, prasasat ora ana wates sosial ing antarane wong loro kuwi." (episode 3: 1)

\section{Terjemahan:}

'Dua orang itu, yang satu sopir dan satunya lagi bos, keduanya tertawa bersamaan, 
terlihat akrab, seperti tidak ada batas sosial di antara keduanya.' (episode 3: 1)

Kutipan di atas menggambarkan keakraban antara Gunar Sudigdo dan Nurcahya. Gunar Sudigdo adalah atasan dari Nurcahya. Nurcahya adalah sopir pribadi Gunar Sudigdo. Namun, hubungan mereka sangat akrab. Gunar Sudigdo tidak membuat jarak antara statusnya dengan status sopirnya, seperti kutipan "Prasasat ora ana wates sosial ing antarane wong loro kuwi". Konteks kutipan di atas yaitu sesaat setelah peristiwa jatuhnya Tyas Widuri oleh sebab Nurcahya yang dengan tiba-tiba membelokkan mobilnya ke arah barat, Gunar Sudigdo menggoda Nurcahya. Gunar Sudigdo menanyakan kepada Nurcahya apakah ada rasa yang istimewa setelah bersalaman dengan gadis yang bernama Tyas Widuri itu, seperti yang tampak pada kutipan "Apa ora ana rasa mirunggan nalika kowe sakloron padha salaman mau?" yang artinya 'apakah tidak ada rasa yang istimewa setelah kalian berdua berjabat tangan?'

\section{Menghormati Orang Lain}

Hormat artinya 1) menghargai (takzim, khidmat); 2) perbuatan yg menandakan rasa hidmat atau takzim (seperti menyembah, menunduk); 3) menaruh (memberi) penghargaan; 4) takzim; sopan (KBBI, 2008: 556). Sikap hormat ditunjukkan oleh para karyawan kepada pemimpin perusahaan, yakni kepada Gunar Sudigdo. Berikut ini kutipannya.

"Para karyawan kang arep dha bali padha aweh urmat marang sang pemimpin perusahaan...." (episode 3: 1)

\section{Terjemahan:}

'Para karyawan yang akan pulang memberi hormat pada pimpinan perusahaan...' (episode 3: 1)

Kutipan di atas menggambarkan sikap hormat karyawan kepada pemimpin perusahaan. Konteks ceritanya ialah saat Gunar Sudigdo kembali ke kantor di sore hari dan saat itu para karyawan sudah saatnya pulang, para karyawan memberi hormat kepada Gunar Sudigdo yang berjalan berpapasan dengan mereka. Sikap hormatnya ditunjukkan dengan tersenyum dan menyapa Gunar Sudigdo.

Sikap hormat juga ditunjukkan oleh Karmidi yang mempersilakan Gunar Sudigdo dan Nurcahya untuk memasuki pendapa. Berikut ini kutipannya.

\section{"...Mangga pinarak rumiyin, dipunentosi} wonten pendhapa kemawon." (episode 7: 2)

\section{Terjemahan:}

'... Mari masuk, ditunggu di pendapa saja.' (episode 7: 2)

Kutipan di atas menunjukkan sikap hormat Karmidi kepada tamu yang datang ke Rumah Dirga Swandaru. Karmidi adalah seorang penjaga rumah. Dia bekerja pada Dirga Swandaru. Saat itu Gunar Sudigdo diantar Nurcahya mendatangi rumah Dirga Swandaru. Pada saat yang sama, Dirga Swandaru sedang kedatangan tamu sehingga Gunar Sudigdo dan Nurcahya harus menunggu. Karmidi dengan sikap yang penuh hormat mempersilakan tamunya untuk menunggu di pendapa. Sikap sopan ditunjukkan dengan kata "Mangga pinarak rumiyin" yang artinya 'mari masuk'. Kata "mangga" ini menjadi di dalam kebudayaan Jawa menjadi indikator sikap sopan. Dengan demikian, si pengujar, Karmidi mempersilakan tamunya dengan penuh sopan santun.

\section{Mempunyai Prinsip Hidup}

Prinsip artinya dasar; asas (kebenaran yang jadi pokok dasar berpikir, bertindak, dan sebagainya); berprinsip artinya mempunyai (menganut) prinsip (2008: 1214). Dalam Cerita Bersambung "Mburu Pusaka" karya Al Aris Purnomo ini, tokoh Gunar Sudigdo dan Nurcahya diceritakan oleh pengarangnya mempunyai prinsip dalam hidupnya. Berikut ini prinsip yang dianut Gunar Sudigdo. 
“...Gunar Sudigdo duwe prinsip yen kesenengane keturutan bakal bisa njaga awak tetep waras...." (episode 4: 2)

\section{Terjemahan:}

'...Gunar Sudigdo mempunyai prinsip bila kegemarannya dituruti, dia akan menjaga diri tetap sehat...' (episode 4: 2)

Kutipan di atas menggambarkan Gunar Sudigdo yang mempunyai prinsip yakni bila kegemarannya dituruti, dia akan menjaga kesehatannya. Dalam Cerita Bersambung "Mburu Pusaka" karya Al Aris Purnomo ini, tokoh Gunar Sudigdo berprofesi sebagai seorang pengusaha. Gunar Sudigdo juga sangat gemar mengoleksi benda-benda pusaka. Jadi, di waktu luangnya, Gunar Sudigdo berburu benda pusaka. Dia berprinsip bila kegemarannya mengoleksi benda pusaka itu dituruti, dia akan menjaga kesehatannya, seperti pada kutipan di atas.

Selain itu, Gunar Sudigdo juga mempunyai prinsip, yakni pemanfataan atas $H P$ yang dimilikinya yang terpenting ialah bisa untuk SMS dan menelepon, tidak peduli bila dikatakan gaptek atau gagap teknologi. Berikut ini kutipannya.

"Hehehe... Aku ora peduli karo kuwi. Sing penting kena kanggo sms lan telpun rak uwis. Aku ya ditawani karo kanca-kanca jarene saiki jamane wis be-be-em... Sms wis ora njaman. Ya wis ben diarani gaptek, sing penting urip ajeg waras. Ora peduli yen jare tehnologi kuwi bisa ngundhakake drajat. Sapa wae sing melek tehnologi bakal katon luwih onjo lan luwih pinter... halah mbelgedhes!" (episode 5: 1)

\section{Terjemahan:}

"Hehehe... Aku tidak peduli dengan hal itu (HP yang sudah usang atau ketinggalan zaman). Yang penting bisa untuk mengirim SMS atau menelepon. Aku juga ditawari oleh teman-teman, katanya sekarang zamannya menggunakan BBM, SMS sudah tidak zamannya. Biar dikata gaptek, yang penting bisa hidup dengan sehat. Tidak peduli kata orang teknologi dapat meningkatkan derajat. Siapa saja yang tahu teknologi akan terlihat lebih unggul dan pintar... halah mbelgedhes!" (episode 5: 1)

Kutipan di atas adalah pernyataan Gunar Sudigdo saat sedang berdialog dengan Nurcahya. Nurcahya menyarankan agar Gunar Sudigdo mengganti HP-nya yang sudah ketinggalan zaman. Namun, Gunar Sudigdo tidak mengindahkan saran itu. Gunar Sudigdo berpendapat bahwa fungsi $H P$ yang terpenting bisa untuk menelepon dan mengirim SMS. Dia juga berprinsip "Ya wis ben diarani gaptek, sing penting urip ajeg waras." yang maknanya 'Biarpun Gunar Sudigdo dikatakan gagap teknologi, dia beranggapan yang terpenting hidup sehat'. Gunar Sudigdo juga tidak peduli dengan perkataaan banyak orang yang berpendapat bahwa teknologi dapat meningkatkan derajat, dan dapat menjadikan orang tersebut unggul dan pintar. Gunar Sudigdo tidak percaya itu semua, dengan berkata "... halah mbelgedhes!"

Selain yang sudah dijelaskan di atas, Gunar Sudigdo juga mempunyai prinsip bahwa kegemarannya mencari pusaka itu untuk mencari kedamaian. Apabila ada hal-hal yang mengoyak kedamaian rumah tangganya, dia akan mencari solusi untuk hal itu. Dia juga mempunyai batasan dalam memuaskan kegemarannnya itu. Berikut ini kutipannya.

“... Anggonku ngupaya pusaka-pusaka iki satemene uga kanggo nggayuh katentreman. Aja kuwatir, aku ngerti wates-watese. Yen nganti ana bab kang nguciwani lan malah gawe goreh utawa ngorak-arik katentreman ing omah iki, mesthi wae bakal dakupaya kepiye amrih becike." (episode 14: 1)

\section{Terjemahan:}

“... Aku mencari pusaka-pusaka ini sebenarnya juga untuk mencari kedamaian. Jangan khawatir, aku tahu batas-batasnya. Bila ada hal yang mengecewakan dan membuat tidak nyaman atau mengoyak 
ketentraman di rumah ini, pasti akan aku upayakan jalan keluarnya." (episode 14: 1)

Berdasarkan kutipan di atas, dijelaskan bahwa Gunar Sudigdo mempunyai prinsip hidup tentang bagaimana ia menyikapi kegemarannya itu, yakni bila kegemarannya itu dapat mendatangkan ketidakdamaian dalam rumah tangganya, ia akan mencari jalan keluar untuk hal itu. Dari penjelasan-penjelasan di atas, dapat disimpulkan bahwa prinsip hidup yang dimiliki oleh tokoh Gunar Sudigdo ialah untuk tetap menjaganya agar terhindar dari keburukan. Dia tetap gemar mengoleksi pusaka, tetapi sepanjang kegemarannya itu tidak membuat kehidupan rumah tangganya berantakan.

\section{Mengutamakan Orang Lain}

Mengutamakan artinya menjadikan utama (memandang, dan sebagainya) utama, menganggap lebih penting (perlu), mementingkan, mendahulukan, menitikberatkan (KBBI, 2008: 1794). Perilaku menguamakan orang lain ditunjukkan oleh tokoh Nurcahya. Berikut ini kutipannya.

"Boten. Mangke mawon, bab niku gampil, sing penting dugi Wonogiri rumiyin." (episode 6: 1)

\section{Terjemahan:}

'Tidak. Nanti saja, masalah itu mudah, yang penting sampai Wonogiri terlebih dahulu.' (episode 6: 1)

Kutipan di atas merupakan cuplikan perkataan Nurcahya yang menolak tawaran Gunar Sudigdo. Saat itu Nurcahya dimintai tolong untuk mengantar majikannya ke Wonogiri. Nurcahya belum sempat makan. Mengetahui hal itu, Gunar Sudigdo menawari Nurcahya agar makan terlebih dahulu. Namun, Nurcahya menolaknya. Ia mengutamakan tujuan utamanya terlaksana, yakni sampai di Wonogiri. Perilaku tersebut menunjukkan perilaku mengutamakan orang lain. Sudah menjadi kewajiban Nurcahya melayani Gunar
Sudigdo. Akan tetapi, persoalan makan juga menjadi persoalan yang tidak boleh diabaikan. Seseorang yang kekurangan asupan nutrisi karena belum makan, badannya akan mudah letih dan lemas. Namun, Nurcahya tidak terlalu mempersoalkan hal itu. Ia memilih untuk melanjutkan perjalanan ke Wonogiri mengantarkan Gunar Sudigdo.

\section{Bijaksana}

Bijak artinya selalu menggunakan akal budinya; pandai; mahir, kemudian bijaksana artinya selalu menggunakan akal budi daya; arif; cermat dan teliti bila menghadapi masalah atau kesulitan. (KBBI, 2008: 198). Pada cerbung ini, tokoh Gunar Sudigdo digambarkan sebagai tokoh yang bijaksana. Contohnya, saat Dyah Pramesthi ingin mengikuti kepergian Gunar Sudigdo ke Wonogiri, Gunar Sudigdo menolaknya dengan halus. Alasan yang disampaikan kepada Dyah Pramesthi juga masuk akal. Berikut ini kutipan pernyataannya.

"Bapak ki ora arep dolan... apa maneh kuwi wayah bengi, apa dina teruse kowe ora kuliyah? Mengko wae yen wis genah urusane bapak rampung, ayo dolan bareng-bareng menyang Wonogiri, plesir nyang Wadhuk Gajah Mungkur", ngendikane Pak Gunar Sudigdo marang Dyah Pramesthi. (episode 16: 2)

\section{Terjemahan:}

"Bapak tidak bertujuan main... apalagi waktunya malam, apa kamu tidak ada kuliah pada hari berikutnya? Nanti saja bila sudah jelas urusannya selesai, ayo bermain bersama ke Wonogiri, bertamasya ke Waduk Gajah Mungkur,' kata Pak Gunar Sudigdo kepada Dyah Pramesthi.' (episode 16: 2)

Kutipan di atas merupakan perkataan Gunar Sudigdo kepada Dyah Pramesthi. Gunar Sudigdo menolak permintaan Dyah Pramesthi yang ingin mengikutinya ke Wonogiri. Gunar Sudigdo beralasan bahwa hari sudah menjelang malam, dan Dyah Pramesthi esok hari- 
nya harus mengikuti perkuliahan. Gunar Sudigdo menjanjikan pada Dyah Pramesthi bila urusannya sudah selesai, ia akan mengajak Dyah Pramesthi mengunjungi Waduk Gajah Mungkur. Pernyataan penolakan GunarSudigdo di atas merupakan contoh sikap bijaksana. Gunar Sudigdo mempunyai alasan yang kuat untuk menolak permintaan anaknya. Ia digambarkan menjadi tokoh yang arif.

Selain kutipan di atas, kutipan di bawah ini juga menunjukkan sikap bijaksana Gunar Sudigdo.

"Kena wae, ning sing ngati-ati, bab-bab sing sekirane gawe kahanan ora becik ya disingkiri wae," tembunge Pak Gunar. (episode 17: 1)

\section{Terjemahan:}

"Boleh saja, asal berhati-hatilah, hal-hal yang sekiranya membuat keadaan tidak baik, ditinggalkan saja', kata Pak Gunar.' (episode 17: 1)

Kutipan di atas merupakan pernyataan Gunar Sudigdo kepada Nurcahya saat Nurcahya meminta pertimbangan kepadanya mengenai keinginan Nurcahya untuk mencari tahu tentang pusaka Nirvashura yang dimiliki Gunar Sudigdo. Dengan bijaksana Gunar Sudigdo mengizinkan Nurcahya. Gunar Sudigdo juga menasihati Nurcahya agar tetap waspada dan berhati-hati terhadap segala tindakannya.

Nurcahya saat itu tidak yakin dengan pusaka Nirvashura yang dimiliki oleh Gunar Sudigdo mempunyai kekuatan yang lebih karena dia tahu ada pedagang patung di pinggir jalan yang menjual patung sama persis bentuknya dengan patung Nirvashura itu. Oleh karena itu, Nurcahya berniat menyelidiki dengan cara menukar patung Nirvashura milik Gunar Sudigdo dengan patung yang sama yang telah dibelinya di pinggir jalan. Nurcahya ingin mengetes kemampuan Dirga Swandaru. Dalam hal ini ingin mengetes apakah Dirga Swandaru bisa membedakan keduanya.

\section{Jujur}

Jujur artinya lurus hati; tidak curang (KBBI, 2008: 644). Gambaran sikap jujur ditunjukkan oleh Nurcahya saat mengakui perbuatannya. Berikut ini kutipannya.

\section{"Patung punika pancen kula lintoni, ngangge patung ingkang kula tumbas wonten pinggir margi." wangsulane Nur- cahya tatag, awit pancen wis samekta kudu kepiye. (episode 18: 1)}

\section{Terjemahan:}

"Patung ini memang saya tukar dengan patung yang saya beli di pinggir jalan,' jawab Nurcahya dengan tabah karena memang sudah disiapkan jawabannya.' (episode 18: 1)

Kutipan di atas merupakan perkataan Nurcahya saat mengakui perbuatannya menukar patung Nirvashura milik Gunar Sudigdo dengan patung yang dibelinya di pinggir jalan. Awal ceritanya, Nurcahya kurang begitu yakin dengan kemampuan Dirga Swandaru. Untuk mengetes kemampuan Dirga Swandaru, Nurcahya menukar patung Nirvashura dengan yang dibelinya di pinggir jalan. Saat Gunar Sudigdo menunjukkan patung itu kepada Dirga Swandaru, ternyata tidak memberikan daya pengaruh apa-apa. Dirga Swandaru mencurigai Nurcahya. Dia meminta Gunar Sudigdo agar menemui Nurcahya dan menanyakan di mana patung yang asli. Saat ditanyai oleh Gunar Sudigdo, Nurcahya dengan tabah menjawab dan menceritakan semua perbuatannya. Dia mempunyai niat baik pada Gunar Sudigdo. Gunar Sudigdo pun tidak marah kepadanya. Gunar Sudigdo mengapresiasi kejujuran Nurcahya.

\section{Cerdik}

Cerdik artinya cepat mengerti (tentang situasi) dan pandai mencari pemecahannya; panjang akal; banyak akalnya (tipu muslihatnya); licik; licin (KBBI, 2008: 279). Tokoh Nurcahya digambarkan sebagai orang yang 
cerdik, dan banyak akalnya. Saat menemui permasalahan, Nurcahya segera mencari pemecahannya. Berikut ini kutipannya.

"Kanoman kuwi sugih akal, kanggo namur laku dheweke tuku ubarampe mancing." (episode 21: 1)

\section{Terjemahan:}

'Pemuda itu banyak akal, untuk menyamar dia membeli perlengkapan memancing.' (episode 21: 1)

Kutipan di atas menggambarkan tokoh Nurcahya yang cerdik. Nurcahya ingin mengintai kegiatan di rumah Dirga Swandaru. Dia menyamar sebagai pemancing agar keberadaannya tidak diketahui penghuni Rumah Dirga Swandaru. Penyamaran Nurcahya berhasil. Namun, ada seorang polisi yang juga sedang melakukan penyamaran mencurigai gerak-gerik Nurcahya. Nurcahya dan polisi itu kemudian berkelahi. Setelah Nurcahya menjelaskan tujuan penyamarannya, polisi akhirnya melepaskan Nurcahya. Nurcahya meminta izin kepada polisi yang bernama Jarmadi itu agar bisa ikut menyelidiki aktivitas Dirga Swandaru. Jarmadi mengizinkan, kemudian mereka saling bertukar nomor telepon. Dari kutipan di atas, dapat disimpulkan bahwa Nurcahya adalah orang cerdik. Dia melakukan penyamaran agar tujuan mencari informasi tentang Dirga Swandaru berhasil.

\section{Moral Buruk}

\section{Mudah Percaya pada Orang Lain}

Percaya artinya memang benar atau nyata; menganggap atau yakin bahwa sesuatu itu benar-benar ada; menganggap atau yakin bahwa seseorang itu jujur (tidak jahat); yakin benar atau memastikan akan kemampuan atau seseorang atau sesuatu (bahwa akan dapat memenuhi harapannya) (KBBI, 2008: 1158). Tokoh Gunar Sudigdo selalu mempercayai perkataan dan perbuatan Dirga Swandaru. Oleh karena itu, Gunar Sudigdo selalu meminta tolong kepada Dirga Swandaru untuk mengecek keaslian pusaka yang dimilikinya. Berikut ini kutipannya.
"Gunar Sudigdo sansaya mantep ka- lamun Dirga Swandaru pancen tenan-te- nan duwe kaluwihan sing mirunggan." (episode 8: 2)

\section{Terjemahan: \\ 'Gunar Sudigdo hatinya semakin mantap bahwa Dirga Swandaru memang benar- benar mempunyai kelebihan khusus.' (episode 8: 2)}

Kutipan di atas menggambarkan Gunar Sudigdo yang semakin yakin bahwa Dirga Swandaru benar-benar mempunyai "kelebihan". Saat itu Gunar Sudigdo meminta tolong kepada Dirga Swandaru agar melacak tempat pusaka Kyai Sengkali, pasangan dari Kyai Branti. Setelah diperiksa oleh Dirga Swandaru, Dirga Swandaru mengatakan bahwa pusaka tersebut yang akan memberikan petunjuk.

Akhirnya, saat tengah malam Gunar Sudigdo, Dirga Swandaru, Nurcahya, dan Dardono mencari keberadaan pasangan Kyai Branti. Mereka menuju ke arah Pracimantoro. Sesampainya di sebuah tempat, mereka turun dari mobil. Mereka mengikuti jalan sempit dan banyak semak-semak belukar. Dirga Swandaru menyingkirkan semak-semak belukar itu dengan goloknya. Hati Gunar Sudigdo semakin yakin bahwa Dirga Swandaru mempunyai kemampuan mencari keberadaan pasangan Kyai Branti usai melihat hal itu.

Selain itu, berikut ini ada kutipan pernyataan Gunar Sudigdo yang percaya tentang kejadian-kejadian aneh yang terjadi pada pusaka koleksinya.
"Yen aku percaya kok, Nur. Percaya kuwi luwih kepenak, ora kakehan mikir." (episode 13: 1)

\section{Terjemahan: \\ "Aku percaya kok Nur. Percaya itu lebih enak, tidak banyak mikir."(episode 13: 1)}


Kutipan di atas merupakan pernyataan Gunar Sudigdo saat mengobrol dengan Nurcahya. Nurcahya dimintai pendapat oleh Gunar Sudigdo berkaitan dengan kejadian aneh yang terjadi terhadap Keris Kyai Branti dan Keris Kyai Sengkali yang bisa berdiri saling berhadapan saat dites kecocokannya oleh Dirga Swandaru. Nurcahya masih merasa ragu dengan hal itu, sedangkan Gunar Sudigdo sangat mempercayai hal itu.

Kenyataannya ialah bahwa kemampuan yang ditunjukkan oleh Dirga Swandaru hanyalah kebohongan belaka. Dirga Swandaru ternyata adalah seorang penjahat. Dia seakanakan mempunyai kelebihan dalam mengetahui keberadaan benda-benda pusaka. Sesungguhnya Dirga Swandaru melakukan tipuan. Itu semua hanyalah trik agar Gunar Sudigdo percaya kepadanya.

\section{Sakit Hati pada Orang Lain}

Sakit hati artinya merasa tidak senang (dendam, benci) karena dihina (dilukai hatinya) (KKBI, 2008: 1343). Sikap sakit hati ini ditunjukkan oleh tokoh yang bernama Dyah Pramesthi. Dia merasa sakit hati saat ayahnya yang bernama Gunar Sudigdo dan sopirnya yang bernama Nurcahya sedang membicarakan Tyas Widuri.Sepertinya gadis yang bernama Tyas Widuri sangat spesial di mata mereka. Berikut ini kutipannya.

"Dyah Pramesthi kepengin takon nanging rasane isin. Atine kenya kuwi krasa mendhekel, ora seneng yen ana kenya liya sing cedhak karo Nurcahya." (episode 13: 1)

\section{Terjemahan:}

'Dyah Pramesthi ingin bertanya tetapi malu. Hati wanita itu sakit, tidak senang bila ada gadis lain yang dekat dengan Nurcahya.'

Pada kutipan di atas, kata "Kenya" merujuk pada Dyah Pramesthi. Dyah Pramesthi merasa sakit hati bila ada gadis yang dekat dengan Nurcahya. Sebenarnya tidak ada hubungan asmara antara Dyah Pramesthi dengan Nurcahya. Akan tetapi, Dyah Pramesthi merasa damai bila di dekat Nurcahya. Dyah Pramesthi mempunyai perasaan khusus kepada Nurcahya. Perasaan yang tidak bisa digambarkan. Oleh karena itu, saat Gunar Sudigdo dan Nurcahya membicarakan wanita lain, Dyah Pramesthi merasa sakit hati. Sakit hati merupakan sikap yang negatif. Seharusnya, Dyah Pramesthi mengingat bahwa antara dia dengan Nurcahya tidak ada hubungan apaapa sehingga rasa sakit hati itu tidak perlu ada.

\section{Menukar Barang Milik Orang Lain}

Menukar artinya mengganti (dengan yang lain); menyilih; mengubah (nama, dan sebagainya); memindahkan (tempat, dan sebagainya) (KBBI, 2008: 1741). Suatu aktivitas menukar dapat dilihat pada kutipan di bawah ini.

\section{"Kanthi sesideman, Nurcahya ngijoli pa- tung Nirvashura sing ana njero kothak nganggo patung kang wingi dituku ana pinggir dalan." (episode 16: 2)}

Terjemahan:

'Diam-diam Nurcahya menukar patung Nirvashura yang berada di dalam kotak dengan patung yang dibelinya di pinggir jalan.' (episode 16: 2)

Kutipan di atas menggambarkan aktivitas Nurcahya yang dengan sengaja menukar patung Nirvashura milik Gunar Sudigdo dengan patung yang dibelinya di pinggir jalan. Saat itu Nurcahya sedang berada di dalam kamar pribadi Gunar Sudigdo. Pada saat Gunar Sudigdo keluar kamar karena ada tamu yang mencarinya, Nurcahya mempunyai kesempatan untuk menukar patung Nirvashura itu. Nurcahya bergegas ke kamarnya mengambil patung Nirvashura yang dibelinya kemudian kembali lagi ke kamar pribadi Gunar Sudigdo. Nurcahya menukar patung miliknya dengan patung Nirvashura milik Gunar Sudigdo. Nurcahya mempunyai tujuan yakni ingin mengukur seberapa kemampuan Dirga Swan- 
daru. Selama ini, pusaka milik Gunar Sudigdo selalu dikonsultasikan pada Dirga Swandaru. Gunar Sudigdo juga sangat mempercayai ucapan Dirga Swandaru. Namun, Nurcahya masih merasa ragu dengan kemampuan Dirga Swandaru sehingga dia ingin mengukur seberapa kemampuannya dengan menukar patung Nirvashura itu dengan patung yang dibelinya. Perbuatan menukar barang milik orang lain adalah perbuatan yang tidak terpuji. Kita tidak mempunyai hak atas barang tersebut. Jadi, lebih baik kita meminta izin pada pemiliknya terlebih dahulu.

\section{Licik}

Licik artinya banyak akal yang buruk; pandai menipu; culas; curang (KBBI, 2008: 924). Pada Cerita Bersambung "Mburu Pusaka" karya Al Aris Purnomo, karakter licik muncul pada tokoh Dirga Swandaru. Untuk mencari keuntungan pribadi, Dirga Swandaru memperdaya orang lain dengan cara berpura-pura menjadi orang yang ahli dalam mengecek keaslian pusaka dan mengetahui pengaruhnya pada kehidupan pemiliknya. Salah satu korbannya ialah Gunar Sudigdo. Namun, Nurcahya berhasil membongkar perbuatan licik Dirga Swandaru. Berkat Nurcahya, Gunar Sudigdo sadar bahwa selama ini dia telah dibohongi oleh Dirga Swandaru. Berikut ini merupakan kutipan yang menggambarkan kelicikan Dirga Swandaru.

"Nurcahya uga nyritakke keterangane polisi Jarmadi, alamun sedyane Dirga Swandaru ora among ngeruk dhuwite Gunar Sudigdo lumantar mburu pusaka, nanging uga nate mbudidaya bakal nyulik Dyah Pramesthi, lan Gunar Sudigdo bakal dijaluki dhuwit tebusan." (episode 23: 2)

\section{Terjemahan:}

'Nurcahya juga menceritakan penjelasan dari polisi Jarmadi bahwa keinginan Dirga Swandaru tidak hanya menguras uang Gunar Sudigdo melalui pemburuan pusaka, tetapi juga pernah mencoba untuk menculik Dyah Pramesthi, dan Gunar
Sudigdo akan dimintai uang tebusan.' (episode 23: 2)

Kutipan di atas menggambarkan saat Nurcahya bercerita kepada keluarga Gunar Sudigdo bahwa berdasarkan keterangan polisi Jarmadi, Dirga Swandaru tidak hanya ingin mengeruk harta Gunar Sudigdo saja, tetapi juga ingin menculik Dyah Pramesthi, kemudian meminta tebusan kepada Gunar Sudigdo. Mendengar keterangan dari Nurcahya, Gunar Sudigdo sangat marah. Ia baru menyadari bahwa Dirga Swandaru ternyata orang yang jahat.

Selama ini, Gunar Sudigdo terpedaya dengan kelicikan Dirga Swandaru. Segala ucapan Dirga Swandaru selalu diikuti. Beberapa pusaka yang ditemukan Gunar Sudigdo ternyata merupakan pusaka pasangan. Artinya, pusaka itu sengaja dipasang oleh Dirga Swandaru agar Gunar Sudigdo selalu meminta tolong kepadanya. Dari kegiatan itu, Dirga Swandaru mendapat keuntungan mahar (bayaran) yang tidak sedikit jumlahnya dari Gunar Sudigdo.

\section{PENUTUP}

Berdasarkan hasil penelitian, dapat ditarik sebuah simpulan yaitu pada Cerita Bersambung "Mburu Pusaka" karya Al Aris Purnomo mengandung nilai moral. Nilai moralnya yakni nilai moral baik meliputi sopan, ramah, percaya adanya Tuhan, menghormati perbedaan pendapat, peduli, rendah hati, akrab antara atasan dan bawahan, menghormati orang lain, mempunyai prinsip hidup, mengutamakan orang lain, bijaksana, jujur, dan cerdik; sedangkan nilai moral buruk meliputi mudah percaya pada orang lain, sakit hati pada orang lain, menukar barang milik orang lain, dan licik. Nilai moral ini dapat diambil manfaatnya oleh pembaca untuk perbaikan sikap dalam kehidupan sehari-hari.

Dengan demikian, bentuk moral baik yang dicontohkan di dalam cerita bersambung ini hendaknya dapat dicerna dengan baik oleh 
pembaca sehingga ada perbaikan sikap yang lebih baik. Sebaliknya, bentuk moral yang buruk sebaiknya dijauhi. Pembaca dapat mengambil hal-hal yang baik dari Cerita Bersambung "Mburu Pusaka" ini untuk dijadikan pedoman hidup.

\section{DAFTAR PUSTAKA}

Darmadi, Hamid. 2009. Dasar Konsep Pendidikan Moral. Bandung: Alfabeta.

Endraswara, Suwardi. 2008. Pengantar Pengkajian Sastra. Yogyakarta: Sewon Press.

Lubis, Mawardi. 2008. Evaluasi Pendidikan Nilai. Yogyakarta: Pustaka Pelajar.

Muchson, Samsuri. 2012. Dasar-Dasar Pendidikan Moral Basis Pengembangan Pendidikan Karakter. Yogyakarta: Ombak Press.

Nurgiyantoro, Burhan. 2012. Teori Pengkajian Fiksi. Yogyakarta: Gajah Mada University Press.
Subroto, Edi. 1992. Pengantar Metode Penelitian Linguistik Struktural. Surakarta: Universitas Sebelas Maret.

Sudaryanto. 1988. Metode dan Aneka Teknik Analisis Bahasa Pengantar Pengumpulan Data. Yogyakarta: Gajah Mada University Press.

Sudjiman, Panuti. 1986. Kamus Istilah Sastra. Jakarta: Gramedia.

Tim Penyusun Kamus Pusat Pembinaan dan Pengembangan Bahasa.2008. Kamus Besar Bahasa Indonesia (KBBI). Jakarta: Balai Pustaka.

Wellek, Rene \& Austin Warren, 1995. Teori Kesusastraan (Terjemahan oleh Melani Budianta). Jakarta: Gramedia Pustaka Utama. 